\title{
Factores de riesgo para infección respiratoria aguda baja grave en Bogotá, 2001
}

\author{
María Belén Jaimes ${ }^{1}$, Diana C. Cáceres ${ }^{2}$, Fernando de la Hoz ${ }^{3}$, Camilo Gutiérrez ${ }^{1}$, \\ Diana Herrera ${ }^{4}$, Jairo Pinilla ${ }^{5}$, Alexandra Porras ${ }^{6}$, Fabio Rodríguez ${ }^{7}$, Martha Velandia ${ }^{8}$ \\ ${ }^{1}$ Grupo de Vigilancia y Control de la Infección Respiratoria Aguda y Meningitis Bacteriana Aguda, Instituto \\ Nacional de Salud, Bogotá, D.C., Colombia. \\ 2 Programa Ampliado de Inmunizaciones, Instituto Nacional de Salud, Bogotá, D.C., Colombia. \\ ${ }^{3}$ Subdirección de Epidemiología y Laboratorio Nacional de Referencia, Instituto Nacional de Salud, Bogotá, \\ D.C., Colombia. \\ ${ }^{4}$ Laboratorio de Virología, Instituto Nacional de Salud, Bogotá, D.C., Colombia. \\ ${ }^{5}$ Hospital San Blas, Bogotá, D.C., Colombia. \\ ${ }^{6}$ Grupo de Vigilancia en Salud Pública, Instituto Nacional de Salud, Bogotá, D.C., Colombia. \\ 7 Universidad de la Sabana, Bogotá, D.C., Colombia. \\ ${ }^{8}$ Centros de Control de Enfermedades, Instituto Nacional de Salud, Bogotá, D.C., Colombia.
}

La gravedad de la infección respiratoria aguda (IRA) es mayor en países en desarrollo, sobre todo entre grupos social y económicamente pobres. Las neumonías virales son las más comunes, especialmente en niños. Con el fin de medir algunos factores asociados con formas graves de infección respiratoria baja realizamos un estudio de casos y controles prospectivo y de base hospitalaria en Bogotá entre noviembre de 2000 y agosto de 2001. Los casos fueron niños entre 2 meses y 5 años que llenaban los criterios de la OMS para IRA grave o muy grave. Los controles eran niños con IRA en el mismo rango de edad, que consultaban al mismo hospital y que no presentaban tirajes. Se estudiaron 638 niños entre los 2 meses y los 5 años de edad (277 casos y 361 controles). Los factores más importantes fueron: vivienda en préstamo (OR=2,7; IC95\%: 1,06-7,07), compartir la cama (OR=1,88; IC95\%: 1,0-3,7), más de 9 personas en la misma casa (OR=1,82; IC $95 \%$ : 1,0-3,51) y fumadores en la vivienda (OR=1,4; IC95\%: 1,0-2,05). Se tomaron 114 muestras nasofaríngeas (niños con 3 días de haber iniciado síntomas) y se obtuvieron virus en 98 de ellas, y se identificó el virus sincitial respiratorio en $41,8 \%$, virus influenza $A$ en $3,1 \%$ y virus influenza $B$ en $1 \%$. El $100 \%$ de los aislamientos positivos para influenza $A$ y $B$ fueron enviados al $C D C$ en Atlanta, donde fueron clasificados como influenza A/PANAMA/2007/99-like e influenza B/SICHUAN/379/99-like, respectivamente.

Palabras clave: neumonía, gravedad, virus, nivel socioeconómico, signos predictores.

\section{Risk factors for low acute respiratory infection in Bogota: a 2001 survey}

Severity of acute respiratory infection is higher in developing countries, especially among the socioeconomically underprivileged. Viral pneumonias are more common, especially among children. A prospective hospital-based case control study was undertaken in Bogota between November 2000 and August 2001, aimed to identify factors related to severe low acute respiratory infection (SLARI). Cases were limited to children aged between 2 months and 5 years who filled WHO criteria for SLARI. Controls were children at the same hospital with ARI in a similar age range, but without symptoms of chest drawing. A total of 638 children (277 cases and 361 controls) were included. The most important risk factors included the following: living in borrowed houses (odds ratio $(\mathrm{OR})=2.7 ; 95 \%$ Confidence Interval $(\mathrm{Cl})$ : $1.06-7.07)$, sharing the bed $(\mathrm{OR}=$ 1.88 , Cl: $1.0-3.7)$, living with more than 9 people $(\mathrm{OR}=1.82$, $\mathrm{Cl}: 1.0-3.51)$, and living with smokers (OR=1.4, $\mathrm{Cl}: 1.0-2.05)$. Of the 114 samples collected (from children at third day after beginning of symptoms), 98 had viruses, sincitial respiratory virus was the most frequently identified virus (41.8\%), followed by influenza $A$ virus $(3.1 \%)$ and influenza $B$ virus (1\%). All positive isolates for influenza $A$ and $B$ were sent to the United States Center for Disease Control 
(CDC) in Atlanta, where they were classified as influenza A/PANAMA/2007/99-like and influenza B/SICHUAN/379/99-like, respectively.

Key words: severity, pneumonia, virus, socioeconomic strata, predicting signs.

La neumonía y la bronquiolitis son responsables de la gran mayoría de muertes por infección respiratoria aguda (IRA) en las áreas menos desarrolladas del mundo, y son el principal motivo de consulta en la práctica médica en los menores de 5 años (1).

La IRA neumónica es una patología causada por una gran gama de agentes etiológicos que han aumentado con el tiempo y forman ya una lista considerable. Entre ellos se encuentran bacterias y virus como agentes principales, aunque también son factibles rickettsias, parásitos y agentes micóticos (2).

Más de 200 virus de 6 familias diferentes causan, aproximadamente, el $70 \%$ de los síndromes respiratorios. Estas familias son: influenza, rinovirus, adenovirus, coronavirus, parainfluenza y virus sincitial respiratorio. Otros que se presentan con menos frecuencia son herpes simplex tipo I, coxsackie, Epstein-Barr, echovirus y poliovirus.

Las neumonías de origen viral son las más comunes, especialmente en niños. Estos virus, especialmente el virus sincitial respiratorio, parainfluenza, influenza y rinovirus, ocasionan una neumonía intersticial, con derrames o condensaciones poco frecuentes que usualmente se presentan días después de un cuadro infeccioso de las vías respiratorias superiores (3).

En Colombia se han presentado picos endémicos de infecciones virales respiratorias; la primera epidemia de influenza registrada y documentada virológicamente se presentó en Ambalema (Tolima) en abril de 1994 cuando de forma repentina se pasó de un promedio normal de 7 a 10 consultas semanales por problemas respiratorios a 200 consultas en una semana. El

\footnotetext{
Correspondencia:

Martha Velandia, Instituto Nacional de Salud, Avenida Calle 26 No. 51-60; teléfono: 220 7700, extensión 111 mvelandia@ins.gov.co

Recibido: 5/11/03; aceptado: 23/05/03
}

$50 \%$ de las 6.278 personas censadas desarrolló la enfermedad. Se estableció una tasa de ataque del $40 \%$ al $50 \%$ y se determinó el virus influenza A/Beijing/32/92 (H3N2) como su causa.

De agosto a noviembre de 1996 se inició en la Costa Atlántica la más grande epidemia documentada en el país desde la pandemia de 1968-69. La epidemia, que se conoció con el nombre popular de 'abrazo del pato', posteriormente se extendió a otras regiones del país, en algunas de las cuales la tasa de ataque fue mayor de $30 \%$, y se calculó cerca de 10 millones de colombianos afectados. El Instituto Nacional de Salud confirmó la circulación del virus de influenza $\mathrm{A} /(\mathrm{H} 3 \mathrm{~N} 2)$, que después el CDC de Atlanta clasificó como A/Wuhan/95 LIKE (H3N2), el cual se aisló de las muestras obtenidas en 10 ciudades, entre ellas Bogotá, Ibagué y Cartagena, y en el departamento de Antioquia.

La aparición de esta epidemia en nuestro país puso en evidencia la necesidad de iniciar un sistema de vigilancia para detectar tempranamente brotes como los descritos anteriormente. El sistema de vigilancia se inició en marzo de 1997 en la División Centro para el Control de Enfermedades y en el Laboratorio de Virología del Instituto Nacional de Salud y en él participan de forma constante Bogotá y Manizales. En estos cinco años de vigilancia de virus respiratorios, se puede observar que tanto el virus de la influenza como el virus sincitial respiratorio no tienen un patrón definido de circulación; por tanto, es importante continuar con la vigilancia para conocer más sobre la dinámica de circulación y las cepas circulantes, así como ampliar la información sobre el comportamiento del virus de influenza en las regiones tropicales.

Hay bastantes evidencias a nivel mundial sobre los factores que influyen en el desarrollo de la IRA, entre los que se incluyen factores socioeconómicos, biológicos y de conocimiento de la madre. Entre los factores socioeconómicos más importantes está el hacinamiento, mientras 
11,9 por asociación con signos de peligro como inhabilidad para beber agua, somnolencia o dificultad para despertar, presencia de convulsión compleja, desnutrición grave, fiebre o hipotermia y estridor laríngeo en reposo. Todos los pacientes procedían de Bogotá y se encontraban hospitalizados en salas de las instituciones seleccionadas para el estudio.

\section{Definición de control}

Los controles se definieron como niños mayores de 2 meses y menores de 5 años con cuadro de IRA de evolución no superior a 15 días, con o sin neumonía, sin tirajes subcostales, procedentes de Bogotá y atendidos en los servicios de consulta externa, urgencias u hospitalización de las instituciones seleccionadas para el estudio.

\section{Criterios de exclusión}

Se excluyeron del estudio a los niños que tuvieran diagnóstico de laringotraqueobronquitis 0 epiglotitis, debido al riesgo de espasmo laríngeo en la toma de hisopado faríngeo. También se excluyeron aquéllos con enfermedades crónicas que favorecieran el desarrollo de neumopatías como el reflujo gastroesofágico, la fibrosis quística, la cardiopatía congénita, el diagnóstico previo de asma y la neumonía recurrente (2 o más episodios de neumonía en un año o más de 3 episodios en total). Los procesos infecciosos diferentes del localizado en el tracto respiratorio, ya fuera superior o inferior, el síndrome broncoobstructivo en niños mayores de 2 años y la no permanencia en Bogotá en los 30 días anteriores al estudio también fueron criterios de exclusión.

\section{Fuentes de información}

La fuente de información utilizada para el estudio fue una encuesta aplicada a las madres o responsables de los menores que consultaron a las instituciones seleccionadas para el estudio y que fueron clasificados como casos o controles. Esta encuesta había sido probada y validada en un trabajo anterior de uno de los investigadores (6). Para aplicarla en el presente estudio se entrenaron dos médicos internos de la Subdirección de Epidemiología del Instituto Nacional de Salud, quienes no sólo recibieron entrenamiento sobre cómo diligenciar la encuesta sino también sobre la importancia de evitar los diferentes sesgos en los estudios epidemiológicos observacionales. Por ello, se les hizo especial énfasis en no dirigir las respuestas de los padres de los pacientes y en recoger de manera similar los datos de las historias clínicas tanto de los casos como de los controles.

\section{Recolección de la información}

A todos los menores seleccionados para participar en el estudio se les aplicó una encuesta previamente validada en la cual se recogieron las siguientes variables:

1. Variables de identificación: nombre, edad del menor y de la madre y procedencia.

2. Factores socioeconómicos: estrato (de acuerdo con el recibo de servicios públicos se clasificaron en alto si el estrato era 506 , medio si era 3 o 4 y bajo si era 1 o 2). Se clasificó el tipo de vivienda según si era propia, arrendada o prestada. También se tuvo en cuenta la calidad de la vivienda según los materiales con que estaban construidas las paredes. Se creó una variable para los servicios públicos en la que se verificaba si la casa tenía servicio de agua corriente o no. Se indagó por el hacinamiento dentro de la vivienda, definido como más de 3 personas por habitación. Otras variables consideradas en la categoría socioeconómica fueron la escolaridad en años de la madre y su ocupación.

3. Factores de riesgo ambientales: tipo de materiales usados para cocinar; lugar de la cocina, presencia y número de fumadores en la vivienda, estado de pavimentación de las calles aledañas a la vivienda.

4. Factores de riesgo alimentario: si hubo lactancia materna y su duración y edad de inicio de alimentación complementaria.

5. Factores de riesgo asociados con la atención médica recibida por el paciente: si hubo o no consulta médica previa por el mismo tipo de episodio; medicamentos recibidos y tiempo durante el cual los recibió; tiempo con la sintomatología antes de ser remitido al hospital. 
6. Hallazgos en el examen físico y durante la admisión hospitalaria: signos y síntomas sentidos por el menor y manifestados por la madre o responsable; frecuencia respiratoria, temperatura y presencia de tirajes subcostales; diagnóstico médico, tratamiento instaurado, institución donde fue atendido y captado para el estudio; clasificación como caso o control.

\section{Recolección de las muestras de laboratorio}

Se tomaron muestras por frotis faríngeo a los niños seleccionados que tuvieran un tiempo de evolución no mayor a 72 horas. Este tiempo de evolución fue fundamental para asegurar una mayor probabilidad de aislamiento viral en las muestras tomadas. Teniendo en cuenta los estudios anteriores, se esperaba recoger muestras faríngeas hasta en $66 \%$ de la población en estudio.

Las muestras se tomaron con escobillones Virocult § (MW 950/974/975 Medical Wire Equipment Co. Ltd.). Las muestras debidamente etiquetadas y los escobillones, introducidos en el mismo tubo, se colocaron en el medio de transporte suministrado y se enviaron en el curso de las primeras 48 horas de tomadas al Laboratorio de Virología del Instituto Nacional de Salud.

En el Laboratorio de Virología del Instituto Nacional de Salud se realizaron pruebas de identificación directa por medio de inmunofluorescencia indirecta (Panel Respiratorio Viral. Catalogo 3105, Chemicon) para los virus influenza, adenovirus, virus sincitial respiratorio y parainfluenza de los grupos 1, 2 y 3 . Además, se realizó cultivo para aislamiento y tipificación por inhibición de hemaglutinación para virus de influenza $A$ y $B$ en las muestras positivas para virus de influenza. Todos los aislamientos positivos de influenza se enviaron a los Centers for Disease Control en Atlanta, GA (EE.UU.), donde se finalizó la clasificación viral y se realizó el control de calidad.

\section{Creación de la base de datos}

Se creó una base de datos en Epilnfo 6.04 donde se almacenó la información recogida en la encuesta según las variables contenidas para su posterior análisis estadístico. Se usó el subprograma Check para crear una rutina y verificar inconsistencias.

\section{Análisis de los datos}

El análisis bivariado se realizó con el fin de establecer asociación entre las variables estudiadas y la presencia de IRA baja grave o muy grave, para lo cual se calcularon las razones de ventajas (OR) y sus intervalos de confianza del $95 \%$ de Cornfield. Para facilitar el análisis, las variables se agruparon en las categorías descritas en la sección de recolección de la información y dentro de cada una de ellas se identificaron aquéllas que tuvieron una asociación con un valor de $p<0,1$ para analizarlas en un modelo de regresión logística.

Las variables dicotómicas se manejaron como tales y algunas de las categóricas y continuas se dicotomizaron teniendo en cuenta la distribución de frecuencias que presentaran, además de la importancia biológica que su agrupamiento pudiera tener en la presencia de IRA baja grave o muy grave.

Para probar diferencias de proporciones en el análisis bivariado se usaron las pruebas de ji al cuadrado de Mantel y Hanzel para variables dicotómicas y ji de tendencia cuando las variables se encontraban en nivel ordinal que mostrara alguna tendencia; además, se hizo un análisis estratificado por edad, sexo y estrato socioeconómico para eliminar posibles confusores, tomando solamente las variables o factores que mostraron significancia estadística.

El análisis multivariado se realizó utilizando la regresión logística incondicional. En el modelo se incluyeron aquellas variables que mostraron tendencia a asociarse estadísticamente con una enfermedad más grave en el análisis bivariado $(p<0,1)$. Para esta modelación se usó el paquete estadístico SPSS.

\section{Aspectos éticos}

La realización de la actual investigación estuvo sujeta al manejo de los datos informados con fines de vigilancia epidemiológica, por lo cual no hubo necesidad de consentimiento informado por parte de los sujetos en estudio. Este tipo de investigación está clasificada como estudio sin riesgo en la Resolución No. 008430 de 1993 del Ministerio de Salud, en la cual se establecen las 
normas científicas, técnicas y administrativas para la investigación en salud (Constitución de 1991, Ley 23,1981 ). Los nombres de los participantes en el estudio se mantuvieron en estricta confidencialidad. Los resultados de las pruebas de laboratorio fueron de libre conocimiento de las instituciones participantes y de los padres de los niños afectados por la enfermedad a quienes les fue tomada la muestra. Cualquier otro uso de esta información, aparte del necesario con fines de planificación en salud pública en las instituciones participantes, necesitará consentimiento escrito del Instituto Nacional de Salud.

\section{Resultados}

Se incluyeron 638 niños entre noviembre de 2000 y agosto de 2001 con edades entre los dos meses y los 5 años de edad (277 casos y 361 controles), seleccionados al azar en la consulta de la mañana y la tarde, durante todos los días de la semana. La selección de los controles se hizo dentro de los 15 días siguientes a la selección de los casos. Las entidades participantes fueron la Clínica del Niño, el Hospital San Blas, Saludcoop, el Hospital El Tunal, el Hospital Militar, el Hospital de Kennedy, el Hospital de Patio Bonito, el Hospital Simón Bolívar, el Hospital Trinidad Galán y la Clínica El Bosque; el mayor número de participantes se captó en la Clínica del Niño del Seguro Social y en el Hospital San Blas.

\section{Factores de riesgo y asociados de tipo biológico, de estilo de vida, ambientales y médicos}

Entre los factores biológicos, el sexo masculino estuvo asociado estadísticamente $(p=0,04)$; la edad de la madre y la del menor no se encontraron significativamente asociadas, aunque la gran mayoría de ellos $(75,5 \%$ de los casos y $73,7 \%$ de los controles) tenía 2 y 12 meses de edad.

El estrato socioeconómico se dividió en tres grupos y se pudo apreciar que la gran mayoría ( $79,1 \%$ de los casos y $80,3 \%$ de los controles) eran de estratos II y III; la tenencia de la vivienda en calidad de préstamo muestra un riesgo 2,7 veces mayor para enfermar de IRA neumonía grave (IC95\%: 1,06-7,07); así mismo, cuando el menor compartía la cama con otras personas, el riesgo fue 1,88 veces mayor (IC95\%: 1,0-3,7), y cuando habitaban más de 9 personas en la misma casa el riesgo fue 1,82 veces mayor (IC95\%: 1,0$3,51)\left(p_{\text {tendencia }}=0,022\right)$. No se encontró asociación para los materiales de construcción de los pisos y las paredes, el acueducto, el tipo de sanitario, el número de cuartos de la vivienda, incluidas la sala y la cocina, y el número de personas por habitación.

En cuanto a los factores relacionados con la escolaridad y la actividad laboral de la madre no se encontró significancia estadística cuando la madre era analfabeta o había cursado cualquier grado de escolaridad aunque se observó alguna tendencia; sin embargo, los IC pasan por 1. Con respecto a quien cuidaba al menor, no hay diferencia entre la guardería o cualquier familiar, incluido el padre.

Con respecto a los factores ambientales, cuando existían fumadores en la vivienda, el riesgo de enfermar gravemente fue 1,4 veces mayor (IC95\%: 1,0-2,05); sin embargo, no hubo diferencia entre cuál de los miembros de la familia era el fumador, tampoco se asoció la ubicación de la vivienda en una calle sin pavimentar, el uso de una habitación exclusiva para la cocina o la ubicación de la cocina en la misma habitación en la que dormía el menor (cuadro 1).

En cuanto a los hábitos alimentarios, el estudio no mostró asociación entre el hecho de haber recibido lactancia materna y la gravedad de la enfermedad, así como tampoco con el tiempo de duración de la misma, lo que se puede explicar por el hecho de que una gran proporción de los menores $(44,8 \%)$ tenía menos de seis meses en el momento de la consulta.

En cuanto a los factores relacionados con la atención médica, la gravedad de la enfermedad no estuvo asociada con la consulta médica previa ni con la remisión al hospital.

Cuando se hizo el diagnóstico por laboratorio, no hubo asociación causal entre la gravedad de la neumonía y la presencia de virus, así como tampoco se evidenció que la gravedad de la enfermedad estuviera relacionada con la presencia de un virus específico. 
El análisis multivariado se realizó utilizando la regresión logística incondicional. Se incluyeron las variables sexo, tenencia de la vivienda, número de personas por vivienda y personas que durmieran en la misma cama del menor objeto de estudio. Las variables que permanecieron asociadas con la enfermedad grave fueron: ser de sexo masculino, vivir en una casa prestada, convivir en una vivienda con más de 9 personas y compartir la cama del menor con otras personas (cuadro 2).

\section{Estimación de la carga de enfermedad respiratoria aguda producida por virus respiratorios}

De las 114 muestras tomadas de los niños con tres días de presentación de síntomas, se obtuvieron virus en 98 de ellas; se aisló virus sincitial respiratorio en $41,8 \%$, virus de la influenza $A$ en $3,1 \%$ y virus de la influenza $B$ en $1 \%$ (cuadro 3).

Todos los aislamientos positivos para virus de influenza A y B fueron enviados a los Centers for Disease Control en Atlanta donde se clasificaron como influenza A/PANAMA/2007/99-like e influenza B/SICHUAN/379/99-like, respectivamente, que corresponden a las muestras tomadas entre el 20 y 21 de noviembre del 2000.

\section{Estacionalidad de la circulación de virus respiratorios}

Se pudo apreciar que el mayor número de muestras se tomaron entre las semanas 46 a 48 del 2000 con una positividad que va del 41 al $48 \%$; en las siguientes semanas disminuyó en forma importante el número de muestras, situación que se puede atribuir a que los menores consultaban después del tercer día de inicio de los síntomas, lo que no permitió el aislamiento viral.

El virus sincitial respiratorio presentó su pico máximo en la semana epidemiológica 48 del 2000 con $48 \%$ de positividad en las muestras tomadas.

\section{Signos y síntomas que mejor predicen Ia IRA baja grave y muy grave}

En el cuadro 4 se muestran los signos y síntomas que presentaron los menores antes de la consulta, cuya información se obtuvo de las madres o responsables de los menores.

A cada uno de ellos se le calculó la sensibilidad y especificidad para evaluar los signos y síntomas predictores de la IRA neumonía grave y muy grave en la población de estudio. La mayor sensibilidad fue en la evaluación de la taquipnea, seguida por la tos y el tiraje. Estos signos son los que más comúnmente se presentan y son los más

Cuadro 1. Variables relacionadas con la gravedad de la IRA baja.

\begin{tabular}{|c|c|c|c|c|c|}
\hline \multirow{3}{*}{$\begin{array}{l}\text { Variables } \\
\text { Género }\end{array}$} & \multicolumn{2}{|c|}{$\begin{array}{c}\text { Casos } \\
\mathrm{n}=277(\%)\end{array}$} & \multicolumn{2}{|c|}{$\begin{array}{l}\text { Controles } \\
\mathrm{n}=361(\%)\end{array}$} & \multirow[t]{3}{*}{ OR (IC95\%) } \\
\hline & & & & & \\
\hline & & & & & \\
\hline Masculino & 172 & $(62,1)$ & 195 & (54) & $1,4(1,02-1,95)$ \\
\hline Femenino & 105 & $(37,9)$ & 166 & (46) & 1,0 \\
\hline \multicolumn{6}{|l|}{ Tipo de vivienda } \\
\hline Prestada & 16 & $(5,8)$ & 8 & $(2,2)$ & $2,7(1,1-7,1)$ \\
\hline Propia-arriendo & 261 & $(94,2)$ & 353 & $(97,8)$ & 1,0 \\
\hline \multicolumn{6}{|c|}{ Personas durmiendo en la misma cama del niño } \\
\hline Adultos, otros niños o ambos & 252 & $(94,4)$ & 322 & $(89,9)$ & $1,9(1,01-3,7)$ \\
\hline Sólo el niño & 15 & $(5,6)$ & 36 & $(10,1)$ & 1,0 \\
\hline \multicolumn{6}{|c|}{ Número de personas en la vivienda } \\
\hline $1-3$ & 56 & $(20,3)$ & 67 & $(18,7)$ & 1,0 \\
\hline $4-8$ & 188 & $(68,1)$ & 271 & $(75,5)$ & $0,8(0,6-1,2)$ \\
\hline $9-15$ & 32 & $(11,6)$ & 21 & $(5,8)$ & $1,8(0,95-3,6)^{\star *}$ \\
\hline \multicolumn{6}{|l|}{ Fumadores en la vivienda } \\
\hline Sí & 98 & $(35,4)$ & 97 & $(27,6)$ & $1,4(1,04-2,05)$ \\
\hline No & 179 & $(64,6)$ & 254 & $(72,4)$ & 1,0 \\
\hline
\end{tabular}

${ }^{* *} p_{\text {tendencia lineal }}=0,02$ 
fácilmente identificados por las madres o responsables ante una enfermedad respiratoria grave que amerite la consulta médica urgente. Sin embargo, éstos presentan unos valores predictivos positivos muy bajos, lo cual indica que en muchas ocasiones no detectan estos signos y síntomas cuando sus hijos están gravemente enfermos. El signo con el valor predictivo positivo y valor predictivo negativo más alto fue el tiraje.

\section{Discusión}

Para determinar los factores de riesgo sociodemográficos, de estilo de vida, ambientales y médicos asociados con la IRA baja grave y muy grave en niños de 2 meses a 4 años se planteó un estudio de casos y controles; se seleccionó la población de estudio en hospitales de atención pediátrica de Bogotá entre los menores que recibieron atención médica en consulta externa,

Cuadro 2. Resultados finales del modelo de regresión logística.

\begin{tabular}{lcc}
\hline Variables & OR (IC95\%) & $\boldsymbol{p}$ \\
& & \\
\hline $\begin{array}{l}\text { Género } \\
\text { Masculino }\end{array}$ & $1,4(0,95-1,9)$ & 0,06 \\
$\quad$ Femenino & 1,0 & \\
Tipo de vivienda & & \\
$\quad$ Prestada & $2,4(1,04-5,9)$ & 0,04 \\
$\quad$ Propia-arriendo & 1,0 & \\
Personas durmiendo en & & \\
la misma cama del niño & & \\
$\quad$ Adultos, otros niños o ambos & $1,8(0,94-3,4)$ & 0,06 \\
Sólo el niño & 1,0 & \\
Número de personas en & & \\
la vivienda & & \\
1-3 & 1,0 & \\
$4-8$ & $0,8(0,5-1,2)$ & 0,22 \\
$9-15$ & $1,7(0,9-3,3)$ & $0,12^{* *}$ \\
\hline${ }^{* *} \underline{p}_{\text {tendencialineal }}=0,08$ & & \\
& &
\end{tabular}

urgencias y hospitalización desde noviembre de 2000 hasta agosto de 2001.

Entre las variables sociodemográficas, el factor más relevante que se observó en $75,5 \%$ de los casos y en $73,7 \%$ de los controles fueron niños entre los 2 y 12 meses de edad, lo que indica la elevada incidencia de la enfermedad en este grupo.

Además, el ser de sexo masculino se encontró asociado con la IRA baja grave y muy grave $(p=0,04)$, resultado que se corrobora con lo dicho por Denny y Victora $(7,8)$, quienes hacen referencia a la relación entre el sexo masculino y la presencia de IRA baja en los estudios de base comunitaria; sin embargo, en los estudios basados en datos de clínicas no puede descartarse la posibilidad de sesgo en razón del sexo al buscar asistencia.

El estrato socioeconómico no se encontró asociado en el presente estudio, pero sí un marcador directo de pobreza como es el tipo de tenencia de la vivienda. Cuando la vivienda es prestada, el riesgo de presentar enfermedad grave o muy grave es 2,7 veces más frecuente $(p=0,019)$, lo cual se corrobora con lo encontrado en el estudio de Victora y colaboradores, en el que se encontró un riesgo 4,59 veces mayor para estratos 0 y I (9).

El hecho de compartir la cama con otras personas, bien sea adultos, niños o ambos, aumenta 1,8 veces la probabilidad de tener enfermedad más grave (IC95\%: 1,0-3,7), lo cual coincide con los resultados obtenidos en el estudio de Cáceres y Alzate realizado en Cali (OR=5,0; IC95\%: 0,66$57,2)$. Resultados similares se obtuvieron cuando se relacionó la convivencia con más de 9 personas en la misma vivienda y la gravedad de

Cuadro 3. Distribución de los resultados virológicos por grupos de edad.

\begin{tabular}{lrrrrrr}
\hline $\begin{array}{l}\text { Grupos de edad } \\
\text { (meses) }\end{array}$ & $\begin{array}{c}\text { Total virus respiratorios } \\
\mathbf{n}\end{array}$ & \multicolumn{1}{c}{$\begin{array}{c}\text { VSR } \\
\mathbf{n}\end{array}$} & $\begin{array}{c}\text { Influenza } \mathbf{A} \\
\mathbf{n}\end{array}$ & $\begin{array}{c}\text { Influenza B } \\
\mathbf{n}\end{array}$ \\
\hline $2-6$ & 16 & $(35,6)$ & 15 & $(36,6)$ & 1 & 0 \\
$7-11$ & 10 & $(22,2)$ & 9 & $(22)$ & 0 & 1 \\
$12-23$ & 11 & $(24,4)$ & 10 & $(24,4)$ & 1 & 0 \\
$24-35$ & 2 & $(4,4)$ & 2 & $(4,9)$ & 0 & 0 \\
$36-47$ & 4 & $(8,9)$ & 3 & $(7,3)$ & 1 & 0 \\
$48-60$ & 2 & $(4,4)$ & 2 & $(4,9)$ & 0 & 0 \\
\hline
\end{tabular}


Cuadro 4. Síntomas y signos predictores de IRA grave o muy grave.

\begin{tabular}{lcccc}
\hline Signos y síntomas & Sensibilidad (IC95\%) & Especificidad (IC95\%) & VPP (IC95\%) & VPN (IC95\%) \\
\hline Taquipnea & $95(91-97)$ & $17(13-21)$ & $47(42-51)$ & $80(69-88)$ \\
Tos & $91(87-94)$ & $9(6-12)$ & $43(39-47)$ & $57(43-70)$ \\
Tiraje & $91(86-94)$ & $81(77-85)$ & $79(74-83)$ & $92(88-94)$ \\
Quejido & $65(59-71)$ & $59(53-64)$ & $55(49-60)$ & $69(63-74)$ \\
Cianosis & $45(39-51)$ & $75(70-79)$ & $58(51-65)$ & $64(59-68)$ \\
Dificultad para deglutir líquidos & $31(26-37)$ & $79(75-83)$ & $54(46-61)$ & $60(56-65)$ \\
\hline
\end{tabular}

la enfermedad (OR=1,82; IC95\%: 0,95-3,51), lo que coincide con el resultado del estudio de Cáceres, en el que se encontró asociado con un OR de 4,05 (IC 95\%: 1,18-14,14) (6).

El humo incluye varios contaminantes que afectan el tracto respiratorio. Las principales fuentes de humo que afectan a los niños en países en desarrollo incluyen la contaminación atmosférica, la contaminación doméstica por residuos orgánicos y la convivencia con fumadores (1).

El humo del cigarrillo contiene cantidades medibles de monóxido de carbono, amoníaco, nicotina, cianuro de hidrógeno, así como diferentes partículas y cierto número de carcinógenos. Las concentraciones de la mayoría de estos productos son mayores en las corrientes laterales del humo que en la corriente principal (10).

La asociación entre el humo ambiental del tabaco en fumadores pasivos y las enfermedades respiratorias en la niñez ha sido claramente establecida por un gran número de estudios (11). Los hijos de los fumadores no presentan tan buenos resultados en las pruebas de función pulmonar y muestran de 1,5 a 2,0 veces mayor incidencia de infecciones respiratorias bajas que los hijos de los no fumadores (12).

En el presente estudio fumar dentro de la vivienda aumentó en $43 \%$ el riesgo de IRA grave en los niños, comparado con los niños en cuya vivienda no había fumadores.

Al estratificar por edad se puede apreciar que factores como la tenencia de vivienda prestada (OR=5,06; IC95\%: 1,53-18,58) y la presencia de fumadores dentro de la vivienda (OR=1,59; IC95\%: 1,03-2,45) aumentaron considerablemente el riesgo de sufrir enfermedad grave en los niños de
2 a 11 meses, en tanto que en el análisis global, el riesgo, a pesar de ser significativo, es menor.

Al estratificar por nivel socioeconómico, el riesgo de sufrir IRA neumonía grave o enfermedad muy grave estuvo asociado con los estratos I y II, y en éstos se encuentra el $71,2 \%$ de la población de estudio. En el estrato I, este riesgo aumentó en los hombres, niños mayores de 6 meses, y en el estrato II, el hecho de compartir la cama con otras personas aumentó el riesgo 1,64 veces en relación con aquéllos que no compartían su cama.

Nuestro estudio presenta algunas limitaciones metodológicas en lo concerniente a la evaluación de factores de riesgo. En primer lugar, algunas de las variables recolectadas, especialmente las variables clínicas, dependen de la calidad de la historia clínica, por ejemplo, los datos sobre la desnutrición. En este tipo de variables, la posibilidad de mala clasificación no diferencial no se puede descartar como una de las causas de no haber encontrado asociaciones importantes con algunas variables que la literatura informa como predictoras de enfermedad grave. Sin embargo, también hay que tener en cuenta que la mayoría de los estudios publicados no usan como controles niños enfermos sino niños sanos, lo cual sugeriría que nuestro estudio tendría la capacidad de identificar las variables con mayor capacidad de discriminar entre pacientes menos graves y más graves. Por otro lado, este tipo de sesgo no invalidaría las asociaciones positivas encontradas en nuestro estudio. Otra limitación es el poder estadístico bajo para detectar como significativas algunas asociaciones que en el análisis bivariado mostraban alguna importancia. Por ejemplo, el número de personas por vivienda, que es un indicador próximo del hacinamiento y de la posibilidad de estar expuesto a más gérmenes, 
no fue significativo en el análisis multivariado, pero el poder estadístico que teníamos en nuestro estudio para detectar diferencias de este tamaño era de menos de $50 \%$. Otros factores como el número de personas que comparten la cama con el niño y el ser de género masculino tenían similares problemas de poder. En síntesis, no podemos descartar que algunos de los factores que tenían asociaciones entre 1,5 y 2,0 no pudieran de alguna manera influir en la enfermedad grave, pero, en todo caso, su influencia no era tan importante como la de aquéllos que sí encontramos asociados.

En cuanto al sesgo de selección, no creemos que éste explique los resultados positivos, ya que los médicos que hacían las admisiones de los casos o los controles no estaban al tanto de la hipótesis del estudio, mientras que los internos recolectores de la información habían sido entrenados para evadir este tipo de error. Mas aún, los datos de una muestra de los casos (30\%) fue revisada una segunda vez por el coordinador de campo del proyecto, y se encontró una concordancia de más del $90 \%$ entre los datos consignados en nuestro formato y los de la historia clínica.

Otro de los objetivos era calcular la carga de enfermedad respiratoria aguda producida por los diversos virus respiratorios y para ello se tenía planeado tomar muestras de laboratorio para hacer aislamiento viral en el 66\% (421) de la población de estudio; sin embargo, sólo se tomaron 114 $(17,9 \%)$ muestras debido a que cuando los menores acudieron a la consulta médica y fueron captados para el estudio tenían más de 72 horas de haber iniciado la sintomatología (criterio de exclusión para aislar algún tipo de virus respiratorio por hisopado nasofaríngeo). Este es un hallazgo importante que debe tenerse en cuenta para futuros estudios, ya que el tiempo de recolección de muestras debe adaptarse para conseguir el número suficiente de ellas.

De las 114 muestras, en $86 \%$ (98) se obtuvo un resultado; el $14 \%$ restante presentaba muy escasas células que no pudieron estudiarse.

De las 98 muestras analizadas, en $44,6 \%$ de los casos y $47,6 \%$ de los controles hubo presencia de virus respiratorios, lo que para un próximo estudio indicaría la necesidad de buscar otros agentes etiológicos de la IRA grave y muy grave, especialmente los de tipo bacteriano y el microorganismo específico con el objetivo de fortalecer las medidas preventivas, especialmente las inmunizaciones.

Un hallazgo importante es que entre el $88 \%$ de los casos y el $95 \%$ de los controles de IRA en los que se documentó la presencia de un virus, éste se identificó como virus sincitial respiratorio, lo cual confirma que este germen es el principal causante de enfermedad respiratoria en niños de Bogotá que acuden a centros hospitalarios, especialmente en los menores de 2 años (83\%), de los cuales el $36,6 \%$ era menor de 6 meses. El segundo agente más frecuente fue el virus de la influenza A, detectado en $8 \%$ de los casos (todos en menores de 2 años) y en $5 \%$ de los controles. El virus de la influenza $B$ se documentó en $4 \%$ de los casos y en ningún control. Los resultados aquí encontrados sobre carga viral son comparables con los hallazgos hechos por Vicente y col. (13), quienes, entre los principales virus detectados, describen el VSR, especialmente en los menores de 6 meses.

Según el informe publicado por Herrera y colaboradores (14), desde 1997, la circulación del VSR en Colombia presenta su pico máximo hacia los períodos epidemiológicos IV y $\mathrm{V}$ de cada año; sin embargo, en el 2000, el comportamiento más elevado fue en el período XI, situación que coincide con la circulación encontrada en el actual estudio.

Nuestro estudio presenta, además, la descripción de los signos y síntomas que mejor predicen la IRA grave y muy grave y que las madres 0 responsables de los niños identifican con mayor frecuencia. Entre éstos se encuentran la taquipnea (sensibilidad $=94,6 \%$ ), la tos (sensibilidad $=91,2 \%$ ) y los tirajes (sensibilidad=90,6\%); estos hallazgos, excepto la tos, superan la sensibilidad encontrada en el estudio de Lanata y colaboradores (15), quienes encontraron para la tos una sensibilidad del 93\%; para las respiraciones cortas y rápidas, una sensibilidad de $75 \%$; para éstas, pero sin bloqueo nasal, del $69 \%$, y para los tirajes subcostales, una sensibilidad de $27 \%$. 
Los resultados obtenidos podrían servir de base para mejorar el enfoque preventivo del programa de control de IRA, ya que permitirán identificar los factores intervenibles asociados y así fortalecer la estrategia de Atención Integral de las Enfermedades Prevalentes de la Infancia (AIEPI), propuestos por la OPS/OMS y Unicef. Utilizando los factores identificados en este estudio, se podría mejorar la estrategia de información, educación y comunicación (IEC) y las acciones de promoción y prevención con el objeto de brindar una atención y manejo institucional adecuado; lograr que las madres y cuidadores de los niños identifiquen oportunamente los signos de alarma y den un adecuado manejo a los niños con IRA en el hogar; promover la coordinación y el trabajo intersectorial que permita el desarrollo general de la población y el mejoramiento de sus condiciones de vida, así como la disponibilidad de intervenciones eficaces de vigilancia en salud pública, con lo que se pueden combatir efectivamente muchos de los factores de riesgo asociados con el estilo de vida totalmente prevenibles y fortalecer los factores protectores que finalmente impactarán positivamente en la reducción de la complicación y la mortalidad por IRA neumonía grave o muy grave en los niños menores de 5 años.

\section{Agradecimientos}

Al Ministerio de Salud de Colombia, que financió parcialmente esta investigación; a Victor Hugo Alvarez, coordinador del Grupo de Vigilancia en Salud Pública del Ministerio de Salud; a Ricardo Luque Nuñez, coordinador del Grupo de Prevención y Control de Enfermedades del Ministerio de Salud; a las directivas y funcionarios de las instituciones participantes que permitieron que esta investigación se realizara: CAMI Patio Bonito, Clínica El Bosque, Clínica del Niño del Seguro Social, Hospital de Kennedy, Hospital Militar, Hospital San Blas, Hospital Simón Bolívar, Hospital El Tunal, Hospital Trinidad Galán y Saludcoop.

\section{Referencias}

1. Victora CG. Factores de riesgo en las infecciones respiratorias bajas. En: Infecciones respiratorias en niños. Organización Panamericana de la SaludOrganización Mundial de la Salud. Washington, D.C.: OPS; 1997. p.7-21.
2. Graham NM, Woodward AJ, Ryan P, Douglas RM. Acute respiratory illness in Adelaide children. The relationship of maternal stress, social support and family functioning. Int J Epidemiol 1990;19:937-44.

3. Donowitz G, Mandell G. Acute pneumonia. En: Mandell G, Bennett JE, Dolin R, editores. Principles and practice of infections diseases. Fifth Ed. London: Churchill Livingstone Inc.; 2000. p.619-37.

4. López-Bravo I, Sepúlveda H, Valdés I. Acute respiratory illnesses in the first 18 months of life. Rev Panam Salud Pública 1997;1:9-16.

5. Millán T, Serani $\mathbf{F}$, Vargas $\mathbf{N}$, Solange $\mathbf{M}$. Características biológicas y sociales de los menores de un año muertos por neumonía en la Región Metropolitana de Chile, 1995. Rev Panam Salud Pública 1999;6:333-41.

6. Cáceres D. Factores de riesgo para hospitalización por neumonia en Cali (tesis). Cali: Universidad del Valle; 1998.

7. Denny FW. Acute respiratory infections in children. En: Etiology and epidemiology. Organización Panamericana de la Salud, Organización Mundial de la Salud. Washington, D.C.: OPS; 1987. p.135-46.

8. Victora CG, Fuch SC, Florez AC, Fonseca, Kirkwood B. Risk factors for pneumonia death among Brazilian children. Int J Epidemiol 1989;18:918-25.

9. Victora CG, Huttly SR, Barros FC, Lombardi D, Vaughan JP. Maternal education in relation to early and late child health outcomes. Findings from a Brazilian cohort study. Soc Sci Med 1992;34:899-906.

10. CDC. 1986 Surgeon's General Report: the health consequences of involuntary smoking. Morb Mortal Wekly Rep 1986;35:769-70.

11. Graham N. The epidemiology of acute respiratory infections in children and adults: a global perspective. Epidemiol Rev 1990;12:149-78.

12. Comitte on Environmental Hazards. Involuntary smoking - a hazard to children. Pediatrics 1986;77:75577.

13. Vicente M. Detección viral en infecciones respiratorias agudas en niños hospitalizados. En: Organización Panamericana de la Salud, Organización Mundial de la Salud. Enfermedades respiratorias en niños. Washington, D.C.: OPS; 1988. p.10-4.

14. Herrera D, De la Hoz F, Mariño C, López JD, Velez C, Arboleda LM. Vigilancia de influenza y otros virus respiratorios en Colombia, enero de 2000 a 31 de julio de 2001. Inf Quinc Epidemiol Nac 2001;6:17.

15. Lanata C, Quintanilla N, Verastegui H. Validity of a respiratory questionnaire to identify pneumonia in children in Lima, Perú. Int J Epidemiol 1994;23:4:827. 